\title{
Servicios públicos, cultura política y protesta ciudadana. El abasto de agua en Aguascalientes, 1899-1944
}

\author{
Francisco Javier Delgado Aguilar*
}

Recibido el 2 de febrero de 2019; aceptado el 3 de abril de 2019

\section{RESUMEN}

El objetivo del artículo es demostrar el surgimiento e importancia de una cultura política urbana vinculada a la introducción del abasto de agua a domicilio en la ciudad de Aguascalientes, capital del estado del mismo nombre, México, durante las primeras décadas del siglo XX. El texto analiza el funcionamiento del sistema de abasto, estudia el surgimiento de organizaciones vecinales y explica los ritmos y estrategias de las movilizaciones ciudadanas que protestaban por la escasez de líquido. La información obtenida en notas de prensa local y en informes, peticiones, quejas y correspondencia localizadas en archivos municipales, estatales y nacionales, apunta a la existencia de un ideal de ciudad que orientó el crecimiento de la capital e influyó en la relación establecida entre gobierno y actores sociales urbanos en un período clave de la conformación del Estado mexicano surgido de la Revolución de 1910 .

Palabras clave: Abasto de agua, cultura politica, historia urbana, movilizaciones sociales.

* Centro Universitario de Investigaciones Sociales, Universidad de Colima, Colima, México, correo electrónico: fdelgado@ucol.mx. ORCID: https://orcid.org/0000-0002-0580-5372. 


\title{
Public services, political culture and citizen protest. The supply of water in Aguascalientes, 1899-1944
}

\begin{abstract}
The objective of the article is to demonstrate the emergence and importance of an urban political culture linked to the introduction of water supply at home in the city of Aguascalientes during the first decades of the 20th century. The text analyzes the functioning of the supply system, studies the emergence of neighborhood organizations and explains the rhythms and strategies of citizen mobilizations protesting the scarcity of liquid. The information obtained in local press releases and in reports, petitions, complaints and correspondence located in municipal, state and national archives, points to the existence of an ideal city that guided the growth of the state capital of Aguascalientes and influenced the relationship established between government and urban social actors in a key period of the conformation of the Mexican State emerged from the Revolution of 1910.

Key words: Water supply, political culture, urban history, social mobilizations.
\end{abstract}

\section{INTRODUCCIÓN Y PLANTEAMIENTO}

$\mathrm{E}$ n este trabajo analizo el origen, composición y actividad de dos organizaciones ciudadanas que durante las décadas de 1930 y 1940 lucharon contra la crónica escasez de agua que aquejaba a los habitantes de la capital del estado de Aguascalientes y denunciaron las tarifas que las autoridades locales cobraban por suministrar el servicio. La primera agrupación se formó en 1936, cuando un grupo de profesionistas y propietarios creó la Sociedad de Usuarios de Agua, que apeló al gobierno federal para arrebatar al ayuntamiento el control del sistema de abasto de agua entubada a domicilio. A principios de 1941 nació una segunda Junta de Usuarios, la cual se componía de obreros y trabajadores de la Colonia Gremial. Ambos grupos organizaron marchas y huelgas de pago e influyeron para que las autoridades locales aceleraran la búsqueda de nuevas fuentes de abasto y cedieran el control del sistema de distribución de agua a las autoridades federales.

Mediante el estudio de los argumentos, prácticas y valores que animaron la acción de ambas sociedades de usuarios, trataré de demostrar la existencia de una cultura política urbana que además de estar vinculada a la introducción de sistemas tecnológicos que crearon una demanda de servicios públicos, definió la relación entre gobierno y grupos sociales e influyó en la transformación de los espacios públicos urbanos durante la primera mitad del siglo XX. 
El análisis de movilizaciones sociales y su relación con la introducción de sistemas tecnológicos, tal y como se plantea en este texto, se vincula estrechamente con la literatura que estudia la historia de los usos del agua en las ciudades, que en años recientes ha experimentado un desarrollo robusto y acelerado, tanto en México como en América Latina, Estados Unidos y Europa.

$\mathrm{Al}$ tomar como punto de partida las diferentes formas en que el agua se ha obtenido, distribuido y utilizado en diferentes entornos urbanos, la literatura en cuestión ha proyectado nuevas luces sobre procesos históricos de largo alcance, tales como la centralización política y la construcción del Estado-nación de cara a los gobiernos locales; el crecimiento de las ciudades y la urbanización de la sociedad; la modificación de los espacios públicos y de los ritmos y lugares en los que se despliega la vida privada de los habitantes de las ciudades y el cambio en las políticas de higiene pública para combatir las enfermedades y epidemias que azotaban periódicamente los centros urbanos.

La historia de los usos del agua también se ha abordado desde la perspectiva de la historia empresarial y la difícil relación entre la gestión pública y privada de los sistemas de abasto. Asimismo, a últimas fechas se ha favorecido el abordaje a partir de la historia ambiental, que destaca la explotación de los recursos naturales y la consiguiente modificación del paisaje urbano, las más de las veces debido a la contaminación de ríos, arroyos y estanques.

El presente texto se alimenta de las aportaciones de este creciente y rico cuerpo de literatura y procura desarrollar una perspectiva distinta a partir del señalamiento de un "punto ciego" común a muchos de estos abordajes. Dicho "punto ciego" se relaciona con el énfasis que la mayoría de los trabajos pone en la construcción de obras públicas y en la oferta (siempre insuficiente) de agua para satisfacer la (siempre creciente) demanda de líquido. Lo que procuro con este texto es enfocar la atención en el proceso histórico que contribuyó a crear un tipo de demanda particular de agua (específicamente del agua entubada llevada directamente a las viviendas y por la cual había que pagar una tarifa al gobierno municipal) y en las consecuencias que el surgimiento de dicha demanda tuvo en el surgimiento de movilizaciones sociales en la ciudad de Aguascalientes durante la primera mitad del siglo $\mathrm{XX} .^{1}$

1 Una relación exhaustiva de trabajos sobre historia de los usos del agua rebasa los propósitos de este texto. Algunos textos fundamentales que ilustran el panorama historiográfico que describo brevemente, son: Aboites, El agua de la nación. Melosi, The Sanitary City y Precious Commodity. Providing water for America's cities. Mates, La conquista del agua. Broich, London. Water and the Making of the Modern City. Contreras-Utrera et al., Agua, 
Las protestas urbanas relacionadas con las deficiencias de los servicios públicos fueron moneda corriente en los años posteriores a la Revolución Mexicana que inició en 1910. Además de Aguascalientes, hubo movilizaciones en las capitales de los estados de Oaxaca, Veracruz y San Luis Potosí, así como en la ciudad de León (en el estado de Guanajuato) y la de México, donde grupos de diferente origen social se organizaron para demandar servicios públicos eficientes y mejorar sus condiciones de vida.

Los trabajos que analizan dichos movimientos toman como referente principal el crecimiento urbano, que devino en la aparición de colonias populares sin servicios públicos como alumbrado, drenaje o agua entubada. ${ }^{2} \mathrm{La}$ transformación urbana y la consiguiente segregación social estuvieron acompañadas de la aparición de nuevos actores y de una "transformación de las maneras de entender y hacer la política". ${ }^{3}$

Los grupos populares fueron protagonistas fundamentales en este nuevo escenario, pues construyeron lazos de identidad y un sentido de comunidad que les permitió identificarse y reivindicar sus demandas como parte de sus derechos ciudadanos. En las ciudades de México, Oaxaca y Veracruz, por ejemplo, fue común que las vecindades, mercados y plazas públicas sirvieran como espacios de sociabilidad en donde las clases trabajadoras se organizaban para protestar colectivamente e incidir en el rumbo de la política. ${ }^{4}$

En este panorama es fundamental considerar la relación entre grupos populares, élites y autoridades urbanas. En la ciudad de México, las organizaciones obreras de fines del siglo XIX adoptaron y reformaron el discurso liberal en aras de legitimar su lucha por mejores condiciones de trabajo. Esta estrategia continuó durante los años de la revolución, cuando los trabajadores reelaboraron un tipo particular de "liberalismo popular" que los acercaba

Estado y Sociedad en América Latina y España. En el caso de Aguascalientes, la historia de los usos del agua en la capital del estado es un tema que apenas comienza a abordarse. Dos libros recientes que abordan la gestión del agua en la ciudad son: Gómez, Remansos de ensueño y Martínez, Cambio y proyecto urbano. Por mi parte, he ensayado una perspectiva que trata de vincular la introducción del sistema de abasto de agua entubada con la modificación de los espacios públicos y la vida cotidiana en el siguiente artículo: Delgado, "Policía urbana, usos del agua y cambio social", pp. 181-199.

2 Smith, Pistoleros and Popular Movements, pp. 268-273. Lear, Workers, Neighbors, and Citizens, pp. 7-9, 17, 29, 34-38, 43-47. Newcomer, Reconciling Modernity, pp. 22-28, 3336, 49, 50. Urbina, “Años veinte”, pp. 28-30, 33, 36, 37.

3 Rodríguez, Historia del desasosiego, p. 29

4 Wood, Revolution in the Street, pp. 213, 214. Lear, Workers, pp. 10-11. Urbina, "Años veinte", pp. 28, 35-42. 
a la ideología de la clase media revolucionaria y les permitía exigir la intervención del gobierno para reforzar sus derechos ciudadanos. ${ }^{5}$

La adopción o rechazo del discurso oficial forma parte de la compleja relación entre Estado y sociedad, factor esencial en la explicación de los movimientos urbanos. En este punto es importante reconsiderar la interpretación que identifica la acción oficial con "mecanismos de control político y legitimación ideológica" y destacar en cambio, la influencia de las reformas y proyectos estatales en las expectativas, valores, comportamientos y formas de organización política de la sociedad urbana. ${ }^{6}$ Se trata en suma, de explorar las "prácticas de interlocución políticas" que están en la base de la relación entre autoridades y grupos sociales que buscan la satisfacción de demandas que en muchos casos son resultado de la misma acción oficial. ${ }^{7}$

En este punto es importante considerar que lo ocurrido en Aguascalientes y México no era ajeno a las tendencias político-sociales del mundo occidental, que para la década de 1930 se decantaban hacia un mayor intervencionismo estatal, la expansión del gasto público y la movilización popular, que llevaron a una crisis terminal a los gobiernos democráticos herederos de la ideología liberal del siglo XIX. En el caso mexicano, el panorama de cambio e inestabilidad fue más patente debido a los efectos del movimiento revolucionario de 1910, que significó — como se mencionó líneas arriba- la entrada decisiva de los grupos populares en la vida política. ${ }^{8}$

Considero que estudiar el abasto domiciliario de agua en la ciudad de Aguascalientes, puede ser útil para pensar los cambios políticos y sociales ocurridos en la primera mitad del siglo XX desde una perspectiva diferente, que tenga como punto de partida la renovada oferta de los programas de provisión de agua entubada y su contribución en la difusión de un "sentido común nuevo" a partir del cual los vecinos "demandaron agua potable y alcantarillado" con la intención de entrar en una forma de vida civilizada que parecía monopolizada por las clases medias y altas. ${ }^{9}$ Como casi siempre, la nueva exigencia rebasó la capacidad de las autoridades para proveer con el nuevo servicio a los habitantes de las ciudades, por lo que se generaron múltiples focos de protesta a lo largo del país. ${ }^{10}$

\footnotetext{
Wood, Revolution in the Street, pp. 91-105, 130, 131, 141, 142, 193, 231.

Rodríguez, Historia del desasosiego, p. 22. Urbina, “Años veinte”, pp. 35, 37, 42, 43.

Rodríguez, Historia del desasosiego, pp. 11, 12, 15, 18-21, 135, 172, 173. Wood, Revolution in the Street, pp. 21, 22, 207, 208.

8 Aboites/Loyo, "La construcción del nuevo Estado, 1920-1945”, pp.595, 620, 621. Hobsbawm, Historia del siglo XX, pp. 117-122.

Aboites, "La ilusión del poder nacional", pp. 182, 185, 186, 193-195.

Aboites, La decadencia del agua, pp. 14-18, 54, 63-65.
} 
Es a partir del análisis de la relación política entre grupos populares, clases altas y autoridades, que se estudian las movilizaciones que protagonizaron los grupos urbanos en Aguascalientes para protestar por la deficiente distribución de agua y los aumentos a las tarifas asignadas a las mercedes domiciliarias. ${ }^{11}$ Aunque las quejas por el servicio fueron recurrentes desde los primeros años del siglo XX, no fue sino hasta la segunda mitad de la década de los treinta que, a la par que se multiplicaban las conexiones domiciliarias, los usuarios comenzaron a organizarse para obligar a las autoridades a mejorar el sistema de distribución, acabar con la escasez de agua y disminuir el costo del servicio.

Además de este planteamiento y unas reflexiones finales, el texto se compone de cuatro partes. En el siguiente apartado describo las principales características del desarrollo demográfico, económico y urbano que experimentó la ciudad de Aguascalientes en las postrimerías del porfiriato y en los años posteriores a la Revolución mexicana. En la tercera parte presento el funcionamiento del sistema de abasto de agua entubada y su impacto en la creación de la demanda de agua a domicilio. Finalmente, analizo en dos apartados el surgimiento, composición, demandas y formas de movilización de la Sociedad de Usuarios de Agua y la Junta de Usuarios de la colonia Gremial.

\section{ECONOMÍAY DESARROLLO URBANO EN AGUASCALIENTES DURANTE LA PRIMERA MITAD DEL SIGLO XX}

Entre 1890 y 1940, la ciudad de Aguascalientes reconfiguró su paisaje, orientación económica y estructura social. La impronta de estas modificaciones influyó en la gestión de los servicios urbanos, la vida cotidiana, la conformación de espacios públicos y las relaciones entre autoridades y grupos urbanos. El crecimiento demográfico sirve como punto de partida para calibrar la naturaleza y alcance de los cambios aquí referidos.

Después de haberse mantenido estable en alrededor de 20 mil habitantes desde 1830, la población urbana comenzó a multiplicarse con rapidez a finales del siglo XIX. Según se desprende de la Tabla l, entre 1873 y 1910 se duplicó el número de habitantes, pasando de 20327 a 45 198. El crecimiento continuó durante la primera mitad del siglo XX y aunque entre 1910 y 1920

11 El término "merced" hace referencia al servicio de abasto de agua que ofrecía el ayuntamiento y que podían contratar los habitantes de la ciudad. Cuando se introdujo el sistema de distribución para llevar agua hasta las viviendas, se generalizó el término "merced domiciliaria”. Había diferentes clases de mercedes y tarifas, según la cantidad de agua y el tipo de vivienda. 
el ritmo disminuyó (con un aumento de tan sólo 2843 habitantes) a partir de 1920 el total se elevó de manera constante. En 1921 había 48041 personas, para 1930 se contaron 62244 y en 1940 había en la ciudad de Aguascalientes 82234 habitantes. Así, Aguascalientes se convirtió en uno de los pocos estados de la república en donde los habitantes de los centros urbanos rebasaban a los del campo.

Tabla 1

Dinámica demográfica de la ciudad y estado de Aguascalientes, 1900-1940

\begin{tabular}{cccc}
\hline Año & $\begin{array}{c}\text { Habitantes del } \\
\text { estado }\end{array}$ & $\begin{array}{c}\text { Habitantes de la } \\
\text { ciudad }\end{array}$ & $\begin{array}{c}\text { \% del total de } \\
\text { habitantes }\end{array}$ \\
\hline 1873 & 89715 & 20327 & 22.6 \\
1900 & 102416 & 34982 & 34.2 \\
1910 & 120511 & 45198 & 37.5 \\
1920 & 107581 & 48041 & 44.7 \\
1930 & 132900 & 62244 & 46.8 \\
1940 & 161693 & 82234 & 50.9 \\
\hline
\end{tabular}

Fuente: Consejo Estatal de Población, 2002, el año del millón. Gómez, Aguascalientes en la historia, 1786-1920, tomos III-V. I, pp. 14 y 16.

Aunado al crecimiento demográfico, la ciudad y el estado experimentaron un inusitado auge comercial e industrial. La renovada actividad comercial debe vincularse con la llegada del ferrocarril a la capital en 1884. El paso del ferrocarril estimuló el rol de Aguascalientes y de su capital como exportadores de maíz, frijol, harinas y sulfato de cobre. ${ }^{12}$ Por su parte, el sector industrial recibió un impulso fundamental en 1895, con la instalación de la Fundición Central Mexicana, así como de los Talleres de Reparación del Ferrocarril Central, que comenzaron a operar en 1900. Los Talleres del Ferrocarril se levantaron al oriente de la ciudad y hacia 1903 ocupaban poco

12 Velasco, Geografía y estadística, pp. 96, 110, 111. 
más de mil obreros. La Fundición Central Mexicana quedó ubicada en el noroeste y en ella laboraban hasta 1500 operarios. ${ }^{13}$

Por su tamaño e importancia, las instalaciones de la Fundición y de los Talleres tuvieron un impacto visual y urbanístico considerable y se convirtieron rápidamente en un punto de referencia para los habitantes, constituyéndose además en una especie de imán que impulsó y orientó el crecimiento de la ciudad durante buena parte del siglo XX. A la sombra del desarrollo industrial, el paisaje urbano comenzó a modificarse con el surgimiento de colonias en el norte y el oriente de la capital. En su mayor parte, estas colonias fueron habitadas por trabajadores e inmigrantes que debieron adaptarse a un entorno urbano hostil y en donde los servicios públicos y la infraestructura eran prácticamente inexistentes. ${ }^{14}$

El desarrollo del sector servicios también volvió notoria la presencia de grupos de clase media, conformados por profesionistas, comerciantes y pequeños empresarios. Muchos eran de orientación conservadora y tenían vínculos políticos e ideológicos con la iglesia católica. ${ }^{15}$

Cada grupo, desde posiciones, intereses, demandas y formas de acción particulares, influyó en la vida política de la capital y estableció vínculos con el resto de los actores urbanos y con las instituciones de gobiernos locales y federales, lo que definiría la evolución del sistema de abasto de agua y la naturaleza misma de la expansión de la ciudad.

El desarrollo industrial y comercial fue interrumpido por la violencia, la inestabilidad política y la movilización social provocadas por la revolución de 1910. El impacto fue notorio a partir de 1914, cuando los habitantes comenzaron a sentir con crudeza la inflación, la escasez de alimentos y dinero circulante, la falta de trabajo y una serie de enfermedades y epidemias que diezmaron a la población del estado. Además de la crisis económica, la lucha armada que inició en 1910 reavivó la lucha de facciones e impulsó la entrada de los grupos populares y de clase media en la vida política local. ${ }^{16}$ Las consecuencias del movimiento revolucionario se entrelazaron con los efectos de la introducción del abasto de agua a domicilio y ambos procesos modificaron los usos del agua, la utilización de espacios públicos y la rela-

13 Bernal, Apuntes históricos, pp. 147, 148, 152, 153. Gómez, Aguascalientes, Imperio de los Guggenheim, pp. 89-91.

14 Sifuentes, "El período 1899-1950", pp. 80, 81, 84. Martínez, Cambio y proyecto urbano, pp. 244, 256-258. Gómez, Aguascalientes en la historia, Tomo III-Volumen I, pp. 70, 72-86, 91, 92. Salazar, El Aguascalientes de antaño, p. 49.

15 Camacho, Controversia educativa, pp. 24, 43, 109, 110, 273, 274. Salmerón, Intermediarios del progreso, p. 68.

16 Gómez/Delgado, Aguascalientes. Historia breve, pp. 186-223. 
ción entre autoridades y grupos urbanos a lo largo de la primera mitad del siglo XX.

\section{SISTEMA DE ABASTO Y CREACIÓN DE LA DEMANDA DE AGUA A DOMICILIO}

Como en muchas otras ciudades del país, durante el siglo XIX funcionó en Aguascalientes un sistema de abasto y distribución de agua en línea. Surgidos en la época colonial, los sistemas en línea se conformaban por manantiales o pozos, cajas de agua en las que se almacenaba el líquido y acueductos o acequias que funcionaban de forma independiente y que distribuían el agua entre los habitantes. En la mayoría de los casos, las acequias eran de madera, mampostería o barro, corrían al aire libre y desembocaban en fuentes ubicadas en plazas y jardines, por lo cual era común que el agua se contaminara o desperdiciara debido al deterioro de la infraestructura. ${ }^{17}$

Como se muestra en el Mapa 1, la ciudad de Aguascalientes se encontraba rodeada de ríos y estanques. Al norte se localizaban dos estanques: el de La Cruz y el estanque Nuevo. El primero era fundamental para el riego de huertas, elemento básico del paisaje y la economía de la capital. Por el norte también corría el arroyo de los Arellano y al sur el arroyo de Los Caleros y del Cedazo. Al oriente se encontraba el manantial del Ojocaliente, principal fuente de abasto de agua para usos domésticos. ${ }^{18}$ Las condiciones geográficas favorecían la distribución del líquido de los manantiales del Ojocaliente, pues la capital se ubica en un valle con dos declives principales: uno que va de norte a sur y otro que corre de este a oeste. Como los del Ojocaliente se ubicaban al oriente de la ciudad, la declinación facilitaba el transporte del agua, que bajaba a la ciudad gracias a la diferencia de altura. ${ }^{19}$

Hacia 1880 había alrededor de 15 fuentes ubicadas en diversos puntos de la capital, principalmente en plazas y jardines. La mayoría se encontraban en la Plaza Principal y el jardín de San Marcos, cada uno con cinco fuentes. El resto se distribuía en las plazas de Zaragoza, el Encino y las calles de la

17 Aboites, El agua de la nación, pp. 75-77. Birrichaga, "Las empresas de agua potable”, p. 192. Camacho, Empresarios e ingenieros, pp. 105-107.

18 Velasco, Geografia y estadística, pp. 23-26. Bernal, Apuntes históricos, p. 325. Díaz de León, “Apuntes”, p. 205. Espinoza, Ligeros apuntes, p. 31.

19 Velasco, Geografía y estadística, pp. 89, 90. Bernal, Apuntes históricos, p. 289, 330 у Espinoza, Directorio de Aguascalientes, p. 8. 


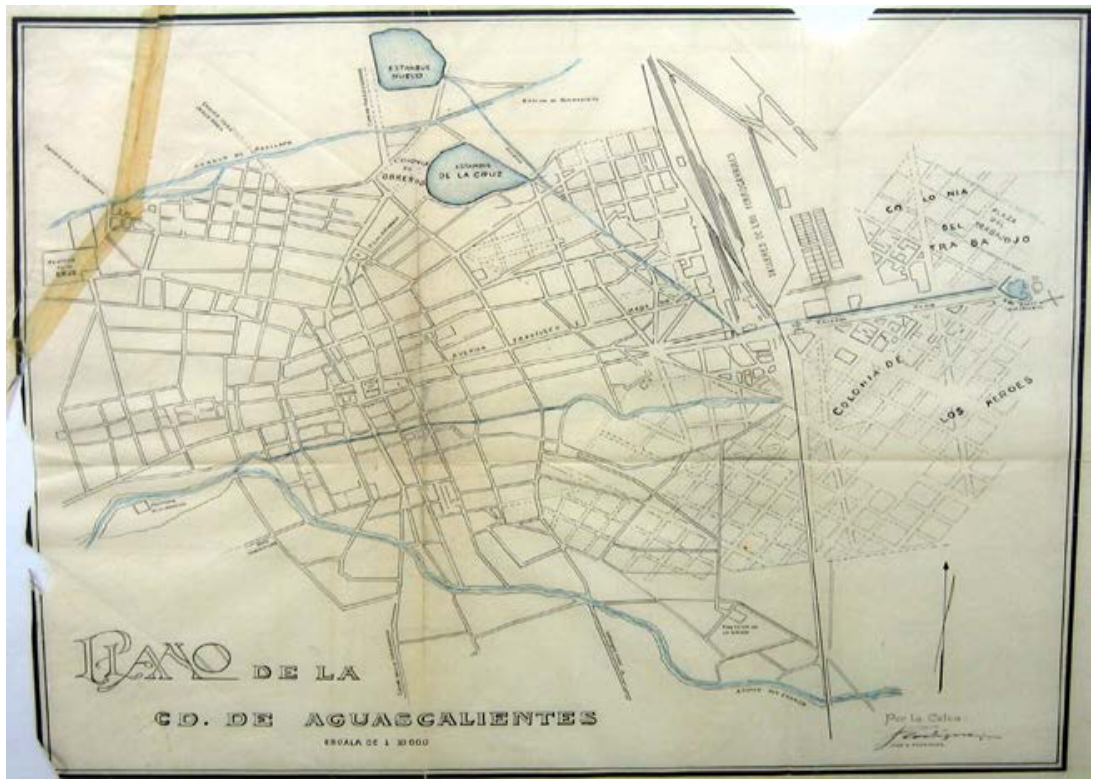

Mapa 1. Plano de la Ciudad de Aguascalientes, México. ${ }^{20}$

Merced, la Cárcel y Obrador, todas ellas cerca del centro de la ciudad. ${ }^{21} \mathrm{El}$ aprovechamiento del Ojocaliente se complementaba - sobre todo en el caso de los usos domésticos - con la existencia de pozos, aljibes y aguadores que traían agua del manantial de Los Negritos, ubicado al poniente de la capital. $^{22}$

El primer paso en la instalación de un sistema en red en la capital se dio en 1899, cuando además de renovar los tanques y acequias principales, se introdujo una tubería de fierro de cinco kilómetros de longitud que llevaba el agua directamente hasta las viviendas de la ciudad. Diez años después se ejecutaron nuevos trabajos que culminaron en la construcción de tres tanques de almacenamiento y una planta de bombeo compuesta por dos salas. El tanque principal se ubicaba a 12 metros de altura con respecto a los manantiales del Ojocaliente y tenía capacidad para guardar 4849 metros cúbi-

Archivo Histórico del Agua, Fondo Aprovechamientos Superficiales, caja 285, expediente 6832.

21 Hornedo, Memoria, (1883-1887), pp. 118-121. "Informe del presidente municipal Felipe Ruiz de Chávez", México, 16 de septiembre de 1882, AGMA, Fondo Histórico, caja 9, expediente 15. "Informe del presidente municipal José Bolado", México, septiembre de 1888, AGMA, Fondo Histórico, caja 162, expediente 35.

22 Díaz de León, “Apuntes”, pp. 192, 205, 206. 
cos de agua. Por otro lado, cada sala de la planta de bombeo tenía dos bombas centrífugas marca Winterthur, que utilizaban motores eléctricos de 10 caballos de fuerza. ${ }^{23}$

En un principio, las tomas domiciliarias se instalaron en el centro de la ciudad, en donde radicaban los grupos de élite y se concentraban los principales edificios públicos y establecimientos comerciales. Con el paso de los años y a pesar de la resistencia inicial de los vecinos, la red de abasto se expandió y aumentó el número de mercedes a domicilio, que comenzaron a cubrir las nuevas colonias obreras ubicadas al oriente.

Lo anterior remite al fenómeno de la creación y difusión de la demanda domiciliaria, pues el servicio se convirtió en una necesidad y fue reivindicado como derecho ciudadano por buena parte de los actores urbanos, incluyendo los de origen popular. ${ }^{24}$ Se creó así un problema de primera magnitud para el ayuntamiento, que debió gestionar un deficiente sistema de abasto cuyas continuas fallas provocaban escasez de agua y descontento entre los vecinos. Se debe agregar además el tema de las tarifas asignadas a las mercedes, pues el cabildo las elevó de forma sistemática durante las primeras décadas del siglo XX, hecho que agravó el descontento.

Varios rasgos definen la forma en que los vecinos exigieron a las autoridades locales mejorar un servicio deficiente y costoso. En la mayoría de las solicitudes enviadas al ayuntamiento subyace una lógica que, a pesar de parecer obvia, influyó de forma determinante en la relación entre usuarios y autoridades y en la evolución del sistema de abasto. El razonamiento se reduce a las siguientes ideas esenciales: cada vecino, al pagar una tarifa mensual por una merced domiciliaria, tiene el derecho de recibir agua potable de forma continua y en la cantidad necesaria para mantener la higiene doméstica y el consumo de cada habitante de la vivienda. En caso contrario, el usuario no estaba obligado a cubrir la cuota impuesta por el ayuntamiento, pues no era justo pagar por un servicio que no se recibía.

Aunque podrían multiplicarse los ejemplos de demandas y quejas de vecinos molestos por la falta de agua, me limito aquí a una solicitud fechada el 10 de marzo de 1936 y firmada por los 53 vecinos de las calles de San Rafael y Primo Verdad. Los peticionarios se dirigían al presidente municipal,

23 "Informe y croquis presentado por el Inspector de Cuarta, C. José S. Rodríguez, con motivo de la inspección que para definir jurisdicción de aguas practico al manantial denominado 'Ojo Caliente' en el Municipio de Aguascalientes", México, 26 de noviembre de 1928, AHA, Fondo Aprovechamientos Superficiales, caja 285, expediente 6832, fs. 3f.-24f.

24 Respecto a este punto es importante el señalamiento de Aboites, quien asegura que los esfuerzos del gobierno y de los grupos sociales sentaron "las bases para nutrir la expansión de los servicios de agua entubada y alcantarillado a lo largo del país, especialmente en las ciudades grandes y medias". Véase Aboites, "La ilusión del poder nacional”, p. 193. 
en uso del derecho que nos concede la Ley para ocurrir a la autoridad en pedimento de la efectividad de los beneficios a que somos acreedores en una sociedad como en la que vivimos en colectividad, pagando nuestras contribuciones e impuestos para el sostenimiento de los gastos públicos, los pagos por el alumbrado en nuestras habitaciones a la Compañía Eléctrica, explotadora, en la esfera de nuestras circunstancias, acomodándonos tolerantemente a cuanto se nos impone para nuestro mejor bienestar.

No obstante, continuaban los vecinos,

el servicio de agua instalada en las casas que habitamos no solo [es] pésimo sino nulo, toda vez que desde las siete de la mañana hasta las siete de la noche no se logra coger ni una sola gota de agua de las llaves, las más de las veces, cuyo indispensable líquido para los distintos usos, nos vemos en la imperiosa necesidad de proveernos de él comprándolo a los vendedores que los introducen en carros, lo que nos es en verdad sumamente gravoso, toda vez que hacemos grandes gastos en esto y pagamos a la vez al municipio.

Por estas razones, y como sabían que "el mal de que adolecemos y nos quejamos de manera formal ante quien corresponde y se dignará oírnos, tiene remedio", los vecinos suplicaban al presidente municipal "que cuanto antes se subsane nuestro mal y perjuicios [...] y es que bombeándose competentemente por la noche el manantial que produce el agua que surte a toda la población, y sólo así será efectivo el abastecimiento para todas las mercedes repartidas y se aplacará el clamor general por ahora, por ser en verdad nulo y gravemente perjudicial el servicio de agua que tenemos". ${ }^{25}$

La petición es significativa porque ilustra varios aspectos de la evolución de la demanda de abasto domiciliario: su creación forzosa (con la "imposición" a la que hacen referencia los vecinos), la apropiación del servicio como un elemento que contribuía a su bienestar y la exigencia de un abasto eficiente y continuo. Este servicio había sustituido la actividad de los aguadores y se reclamaba como un derecho, pues por él se pagaban los impuestos que servían para "sostenimiento de los gastos públicos".

Los habitantes también señalaban las principales causas de la falta de agua. Los argumentos para explicar la insuficiencia del líquido son importantes porque forman parte de una "noción de escasez", concepto esencial del discurso con el que legitimaban sus demandas y quejas. Los vecinos indicaban tres motivos para explicar la escasez: las fallas en el sistema de

25 "Vecinos de las calles San Rafael y $1^{\mathrm{a}}$ y $2^{\mathrm{a}}$ de Primo Verdad solicitan que el servicio de agua sea efectivo", México, 10 de marzo de 1936, AGMA, Fondo Histórico, caja 1001, expediente 20 , fs. $156 f$. 
abasto provocadas por la ausencia de mantenimiento; la incapacidad de los empleados encargados de manejar el sistema de tuberías y llaves de distribución y la presencia de huertas.

Con respecto a la primera causa, es ilustrativa una carta de 1941, en la que varios habitantes de la calle de Terán criticaban la injusticia que implicaba la distribución deficiente del agua y pedían al gobernador averiguar por qué sólo había

agua de las 6 a las 6 y 45 cada tres, cuatro o cinco días [...] porque si se dispone del servicio en la forma indicada, con un poco de buena voluntad se haría el servicio con equidad, porque pagamos como todos los usuarios y sufrimos consecuencias horrorosas por la falta del agua y como esto se presta para ciertos abusos recibimos perjuicios por todos lados, en primer lugar la falta del líquido y la otra un gasto separado para comprar el agua que no se recibe y en cambio la cobran en la oficina respectiva.

Los quejosos aseguraban que si había agua "para un corto rato, con una buena repartición [...] podría haber agua hasta las diez de la mañana siquiera, pues según nuestra humilde opinión es cuestión de arreglo en el asunto [...] ya que en otras partes se desperdicia de una manera enteramente inconveniente". ${ }^{26}$

Algo similar ocurrió con las huertas, que además de ser criticadas en nombre de la higiene y el crecimiento urbano, se les acusó de contribuir a la falta de agua. Una protesta que 24 habitantes de la calle de Oriente presentaron en mayo de 1921 ilustra esta noción de escasez y remite a los derechos creados por el pago de mercedes domiciliarias, así como a la preferencia que - según los quejosos - debía otorgarse a los usos domésticos por encima de los agrícolas. Los vecinos habían contratado el servicio antes de que fuera declarado obligatorio y después de no recibir líquido durante varios días, decían sufrir graves perjuicios, pues "el agua es quizá lo más indispensable para todos los usos de la vida”. Según los quejosos,

la falta de agua obedece a las numerosas concesiones de mercedes de agua dadas a huertas por el rumbo de San Marcos y adyacentes que controlan la mayor cantidad de agua y presión por estar en la parte más baja del tubo principal, y que naturalmente que ahora, con el excesivo calor que hace, tienen abiertas sus llaves día y noche para regar sus terrenos, consumiendo por lo

26 "Vecinos de la calle de Terán, representados por Vicente Delgado, escriben al gobernador del estado", México, 11 de octubre de 1941, AHEA, Fondo Poder Ejecutivo, Secretaría General de Gobierno, caja 461, legajo 1, expediente 2. 
mismo una gran cantidad de agua y quitándole la necesaria presión para que pueda llegar hasta nuestro rumbo, colocado como ya quedó dicho, en la parte final del tubo que abastece a toda la ciudad.

Lo anterior era doblemente agraviante porque los vecinos sostenían haber pagado "con la debida oportunidad las mercedes de agua que se han servido fijarnos, sin que recibamos como ahora absolutamente nada de ese líquido, o en cantidad muy limitada cuando llega hasta nosotros". En consecuencia, los inconformes de la calle de Oriente elevaban ante los regidores del ayuntamiento

una enérgica protesta [...] esperando que con dicha protesta ustedes, que son los encargados de velar por nuestros intereses y por los intereses del municipio, pondrán inmediato remedio a los males que dejamos apuntados, dictando las medidas radicales encaminadas a suprimir en lo absoluto el abuso cometido con dar concesiones de agua a huertas de ninguna clase, cuando falta esa agua en domicilios particulares que deben tener absoluta preferencia. ${ }^{27}$

Finalmente, debe señalarse la formación de asociaciones y sociedades que agrupaban a los habitantes de una cuadra o barrio al momento de exigir un abasto eficiente de agua. Esta organización vecinal fue otro factor fundamental que permitió a los habitantes de las colonias populares presentar y legitimar sus demandas ante la autoridad local. Dicha organización — informal y en ocasiones pasajera - permitía a los quejosos respaldar hasta con 100 firmas las peticiones que enviaban al ayuntamiento.

Destaca en este panorama la junta vecinal de la colonia San Marcos, una de las que tuvo mayor presencia en la década de los cuarenta. La organización contaba con una mesa directiva que agrupaba a personalidades como el ex gobernador Enrique Osornio y se allegaba fondos mediante la recaudación de cuotas entre los vecinos del barrio. Además de ocuparse de mejorar servicios como los de alumbrado público, drenaje y agua, los miembros de la junta impulsaron la construcción de una escuela y el mejoramiento de la vigilancia por parte de la inspección de policía. ${ }^{28}$

Al expandirse la demanda, adoptarse el servicio como un derecho ciudadano y robustecerse la organización vecinal, se conjuntaron los elementos necesarios para originar movilizaciones urbanas que reclamaron directamente al gobierno local y federal una mejora sustancial del servicio de abasto de agua.

27 "Protesta de varios vecinos de las calles de Oriente por mal servicio de agua", México, 17 de mayo de 1921, AGMA, Fondo Histórico, caja 505, expediente 60, fs. $7 \mathrm{f}$.

28 El Sol del Centro, Aguascalientes, 13 de diciembre de 1945, 7 de enero, 20 y 25 de mayo de 1946. 


\section{LA SOCIEDAd de USUARIOS DE AgUAS FEDERALES}

La Sociedad de Usuarios de Aguas Federales (en adelante SUAF) nació el 27 de junio de 1936, al amparo de una nueva Ley de Aguas que autorizaba la creación de organizaciones ciudadanas para gestionar sistemas de abasto de agua en las ciudades. La mayoría de los 40 miembros fundadores de la asociación eran comerciantes, ingenieros, abogados y médicos. ${ }^{29} \mathrm{Al}$ referirse a la Sociedad, un funcionario del gobierno federal aseguró que estaba compuesta por "los elementos honorables de la ciudad de Aguascalientes encabezados por profesionistas, en su mayoría ingenieros, con pleno conocimiento de sus deberes". ${ }^{30}$

En el acta de fundación, los miembros de la organización asentaron que era del "dominio público" que a pesar de las altas tarifas que imponía el ayuntamiento, sólo el 50\% de las casas de la ciudad recibía "una cantidad inapreciable de agua". Por este motivo, declararon que su principal aspiración era obtener un servicio de agua eficiente, barato y que estuviera al alcance de todas las clases sociales. Esta reivindicación la presentaban desde su condición de "ciudadanos en pleno goce de sus derechos civiles". ${ }^{31}$

Los miembros de la organización también exigían que el agua distribuida fuera potable. Para demostrar que el líquido no era apto para consumo humano, presentaron un estudio realizado a instancias del Club Rotario y firmado por el médico Manuel Bosque. Según el análisis, el agua que provenía del manantial del Ojocaliente era "malsana, impura y peligrosa", lo que ocasionaba "el aumento del coeficiente de morbilidad y mortalidad en la ciudad".

La Sociedad de Usuarios señalaba al ayuntamiento como el responsable de las notorias deficiencias en el servicio. Además de administrar ilegalmente el sistema de abasto - ya que no había cumplido con los requisitos establecidos por el gobierno federal para confirmar el aprovechamiento que hacía del manantial del Ojocaliente- el cabildo nunca se había preocupado por renovarlo o mantenerlo en buenas condiciones. Así, y ya que la nueva Ley de Aguas "facultaba al pueblo para que independientemente administre" el servicio de agua, la SUAF consideraba que la única solución a los pro-

29 "Acta y Bases Constitutivas de la Sociedad de Usuarios de Aguas Federales para Usos Públicos y Domésticos de la Ciudad de Aguascalientes”, México, 12 de octubre de 1936, AHA, Fondo Aprovechamientos Superficiales, caja 4877, expediente 67890, fs. 132f.-159f.

30 "Del Agente General en Celaya, Ignacio Jaime, al Director de Geografía", México, 21 de septiembre de 1936, AHA, Fondo Aprovechamientos Superficiales, caja 4877, expediente 67890 , fs. 322f.

31 "Acta de fundación de la Sociedad de Usuarios de Aguas Federales", México, 27 de junio de 1936, AHA, Fondo Aprovechamientos Superficiales, caja 4877, expediente 67890, fs. 317f.-320f. 
blemas que aquejaban al sistema era ponerlo en las manos "absolutamente honradas" de su Junta Directiva. Con la ayuda "de instituciones tan honorables como la Cámara de Comercio, el Club Rotario, Asociación Agrícola de Estableros y Ganaderos y demás fuerzas vivas de la Localidad", se aseguraba que la organización administraría con eficiencia el servicio. ${ }^{32}$

En sus bases constitutivas, la SUAF también prometía que en caso de que el gobierno federal le cediera la gestión del sistema de abasto, "la ministración del servicio no tendrá propósitos de lucro", pues las cuotas "sólo tenderán a cubrir los gastos de amortización de las obras y equipo que necesiten reemplazo, los de conservación y administración y la constitución de un fondo de reserva". En el mismo documento se proponían tarifas notoriamente más bajas que las establecidas por el ayuntamiento (las mercedes de primera clase, por ejemplo, costarían 2 pesos mensuales, mientras que el cabildo cobraba por las mismas 5 pesos) y se advertía que quedarían "suprimidas toda clase de taxativas y recargos por concepto de notificaciones". ${ }^{33}$

Según la SUAF, resultaba fundamental eliminar el "interés especulativo" que el ayuntamiento había fijado al servicio de agua, convirtiéndolo en un "negocio" que producía entradas extraordinarias cuyo destino se desconocía. La organización también criticó los medios "tiránicos" del cabildo para cobrar las tarifas, tales como "recargos, gastos de sobrante, embargo y remate de bienes". 34

Negarse a cubrir el costo asignado a las mercedes de agua fue la principal forma de protesta de la SUAF en contra de la gestión municipal del servicio de abasto. A finales de 1937, cuando el ayuntamiento elevó de nuevo las tarifas para obtener recursos extraordinarios que permitieran la renovación del sistema de abasto, la sociedad declaró una "huelga de pagos". El 3 de enero de 1938, el presidente municipal Alberto del Valle acusó a la Sociedad de instigar a los "mercedados de aguas" para "que no paguen las cuotas que conforme al Plan de Arbitrios autorizado por la H. Legislatura del Estado se deben hacer efectivas". ${ }^{35}$

32 "De Carlos Álvarez, presidente de la Asociación Agrícola Local, al Director del Departamento de Estudios Geográficos", México, 6 de noviembre de 1936, AHA, Fondo Aprovechamientos Superficiales, caja 4877, expediente 67890, fs. 86f.-89f.

33 "Acta y Bases Constitutivas de la Sociedad de Usuarios de Aguas Federales para usos Públicos y Domésticos de la ciudad de Aguascalientes”, México, 12 de octubre de 1936, AHA, Fondo Aprovechamientos Superficiales, caja 4877, expediente 67890, fs. 132f.-159f.

34 "Del presidente de la Sociedad de Usuarios Blas Romo al Secretario de Agricultura y Fomento", México, 29 de junio de 1936, AHA, Fondo Aprovechamientos Superficiales, caja 4877, expediente 67890, fs. $316 f$.

35 "Del presidente municipal Alberto del Valle al Secretario de Agricultura y Fomento", México, 3 de enero de [1938, AHA, Fondo Aprovechamientos Superficiales, caja 4877, expediente 67890 , fs. $234 \mathrm{f}$. 
A los pocos días, la Sociedad de Usuarios confirmaba ante el secretario de Agricultura y Fomento la suspensión de los pagos por el servicio de agua y aclaraba que no cubriría ninguna cuota hasta que el ayuntamiento se sujetara a la Ley de Aguas, "fiados en que Usted, que es la autoridad a quien compete hacerla respetar, obligará al Ayuntamiento a que la cumpla y nos dará la administración de dicho servicio para mejorarlo económicamente y no gastando millones de pesos sin necesidad". ${ }^{36}$

A pesar de la presión de la SUAF, el gobierno federal no obligó al ayuntamiento a cumplir con la ley y disminuir las tarifas de las mercedes de agua. Además, se mostró renuente a reconocer oficialmente a la Sociedad de Usuarios, lo que le hubiera permitido a dicha organización desplazar al ayuntamiento en la administración del servicio de abasto.

Mientras la inacción del gobierno federal frenaba el activismo de la SUAF, tomaba fuerza la presencia de los ferrocarrileros, quienes a principios de enero de 1938, a través de la sección 2 del Sindicato, llamaron "a todos los trabajadores organizados y pueblo en general" a una "grandiosa manifestación popular de protesta contra las nuevas gabelas que sobre servicio de agua, de carne, etc., ha impuesto el gobierno local, gravando con esto la ya de por sí miserable vida de nuestro pueblo".

La marcha se programó para el domingo 16 de enero. Un día antes, el Sindicato convocó a una asamblea preparatoria a la que asistieron tres mil personas. En dicha reunión se repartió un "Manifiesto" en donde se sostenía que el pueblo de Aguascalientes se había "rebelado contra un plan de arbitrios que viene a convertir en artículos de lujo la carne, la leche y algunos otros [productos] que por su precio se elevan tanto que hacen imposible su adquisición". ${ }^{37}$

Es importante mencionar que la SUAF se deslindó de las protestas del sindicato y rechazó la versión que circulaba "en las esferas oficiales del estado de Aguascalientes (que) dice que nosotros con el pretexto del alza de cincuenta centavos en cada merced de aguas, estamos haciendo política, que somos Cedillistas; pero nosotros no tenemos ligas ningunas con el Sindicato de Trabajadores Ferrocarrileros". ${ }^{38}$ No obstante este deslinde, la

36 "La Sociedad de usuarios escribe al Secretario de Agricultura y Fomento", México, 10 de enero de 1938, AHA, Fondo Aprovechamientos Superficiales, caja 4877, expediente 67890, fs. 350 f.

37 "Sindicato de Trabajadores Ferrocarrileros de la R.M. Sección No 2. Aguascalientes, Ags. Manifiesto a todos los trabajadores y pueblo en general", México, 15 de enero de 1938, AHA, Fondo Aprovechamientos Superficiales, caja 4877, expediente 67890, fs. 307f.$3130 \mathrm{f}$.

38 Muy probablemente, la acusación de "cedillistas" tenía como fin desprestigiar a la Sociedad, al vincularla con el movimiento encabezado por el cacique y gobernador de San Luis Potosí, 
SUAF disminuyó su activismo y perdió protagonismo en la escena política local. Según una enigmática declaración de Evaristo Femat, la sociedad había suspendido sus actividades en julio de 1938 "por razones que no nos atrevemos a exponer". A partir de este momento, la estafeta de las protestas urbanas pasó a manos de los trabajadores del ferrocarril. ${ }^{39}$

\section{LAJunTa de USuARIos de AguA de la COLONIA Gremial}

Muchos de los miembros del sindicato ferrocarrilero habitaban en la colonia Gremial y vivían agobiados por la permanente escasez de agua, por lo que no resulta extraño que continuaran - con diferentes recursos y estrategiaslas protestas de la Sociedad de Usuarios. En mayo de 1941, los vecinos de la Gremial crearon la Junta de Usuarios de Agua de los Manantiales del Ojocaliente (en adelante JUA). A diferencia de la SUAF — conformada por propietarios de clase media y alta que apelaron sobre todo al gobierno federal-, los ferrocarrileros acudieron a la acción directa para hacer sentir su presencia en el escenario político urbano. Además, legitimaron sus demandas mediante una retórica revolucionaria que aludía constantemente a la Constitución de 1917.

La actividad de la JUA respondía a los ciclos de escasez de agua, que en la capital se agudizaban entre abril y agosto. En dichos meses, los miembros de la sociedad redoblaban sus protestas, escritos y manifestaciones, para después entrar en una especie de pausa invernal. ${ }^{40} \mathrm{La}$ renovación del personal del ayuntamiento a principios de año era otra oportunidad que la Junta aprovechaba para plantear sus demandas ante las nuevas autoridades y presionarlas para que solucionaran las fallas en el sistema de abasto.

Las peticiones de los vecinos de la colonia Gremial guardaban varias semejanzas con las reivindicaciones que la SUAF había presentado algunos años antes. Ambas organizaciones criticaban las elevadas tarifas adjudicadas a las mercedes de agua, la distribución ineficiente que provocaba escasez de líquido y el creciente deterioro del sistema de abasto.

Saturnino Cedillo, que justo por estas fechas se había distanciado del gobierno federal y preparaba una fallida y breve insurrección militar". Ver: Falcón, Revolución y caciquismo en San Luis Potosí, pp. 264-270.

39 "De Evaristo Femat al Secretario de Agricultura, José Parres", México, 18 de enero de 1938, AHA, Fondo Aprovechamientos Superficiales, caja 4877, expediente 67890, fs. 305f.-305f.

40 A inicios de 1943, por ejemplo, uno de los miembros de la Junta de Usuarios sostenía que "en estos meses más o menos tenemos agua, aunque sea poca, pero llegando las fiestas de abril, se escasea por completo". Ver: "Asamblea celebrada entre el ayuntamiento de la capital y los miembros de la Junta de Usuarios de Agua", México, 28 de enero de 1943, AGMA, Fondo Histórico, caja 957, expediente 6, fs. 9f.-17f. 
Sin embargo, los colonos de la Gremial pusieron especial interés en que el ayuntamiento condonara sus adeudos por no cubrir las tarifas impuestas a las mercedes de agua y dejara de cancelar las conexiones domiciliarias por dicha falta de pago. Además, sostenían que el carácter civilizado de la ciudad dependía de la existencia de un servicio de agua eficiente que proporcionara agua para todos los habitantes. Por esta razón esperaban que en "un plazo razonable se nos suministre el preciado líquido y así vivir como los pueblos civilizados, porque creemos tener el mismo derecho". ${ }^{41}$

Reivindicar la condición de ciudadanía fue otro paralelismo importante entre el discurso de la Junta de la colonia Gremial y el de la SUAF. No obstante, a diferencia de esta última, la JUA aludía a la Constitución de 1917 como el origen de su derecho ciudadano a un servicio de agua eficiente. Otra diferencia fundamental reside en que para los colonos de la Gremial, la principal causa de la escasez de agua eran los baños públicos, principalmente el de Los Arquitos, propiedad del juez de distrito Leopoldo Estrada. Haciendo eco de la crítica que con anterioridad habían desplegado grupos de vecinos e incluso el mismo ayuntamiento, la JUA sostenía que los baños eran "antihigiénicos" y desperdiciaban grandes cantidades de líquido, que podrían bastar para asegurar un suministro de agua suficiente para todos los habitantes.

En este tenor, la JUA exigió al cabildo restringir el abasto de agua a los baños y que incluso procediera a su compra y posterior clausura, para así destinar todo el producto del manantial del Ojocaliente para los usos domésticos de los vecinos. ${ }^{42}$ En caso de que el ayuntamiento no tomara cartas en el asunto, la JUA advirtió que recurriría a la "agitación del pueblo" para "gestionar" el cierre de los mencionados baños. ${ }^{43}$

Como los meses pasaron y el problema no se solucionaba, a finales de mayo y junio de 1943, tuvieron lugar las anunciadas protestas públicas que las autoridades calificaron de "amenazantes y tumultuosas". El primero de junio, el presidente municipal Francisco Revilla envió el siguiente telegrama al Banco Nacional Hipotecario y de Obras Públicas:

Pueblo esta ciudad sumamente excitado por falta de agua tratando unificar todos sindicatos y demás sectores a fin hacer manifestación pública y recurrir si

41 "Del presidente de la Junta de Usuarios, Pedro Covarrubias, al presidente municipal", México, 29 de enero de 1943, AGM, Fondo Histórico, caja 958, expediente 3, fs. 9f.-10f.

42 "El presidente de la Junta de Usuarios, Isidro Mora, escribe a Manuel Ávila Camacho", México, 26 de julio de 1941, AHEA, Fondo Poder Ejecutivo, Secretaría General de Gobierno, caja 461 , legajo 1 , expediente 2 .

43 "Entrevista que tuvieron el presidente municipal y el presidente de la Junta de usuarios de los manantiales del Ojocaliente", México, 23 de mayo de 1942, AGMA, Fondo Histórico, caja 1067 , expediente 19 , fs. 251 f.-256f. 
necesario a medios violentos objeto presionar autoridades locales y federales a efecto se les atienda sus necesidades. Con toda urgencia del caso suplícole violentar nuevo servicio que debe instalarse esta ciudad mayor brevedad. ${ }^{44}$

Desconocemos en detalle el desarrollo de las manifestaciones, pero los testimonios disponibles indican que el descontento de los participantes se enfocó sobre todo hacia los baños de Los Arquitos. El 12 de junio, el periódico Provincia informó sobre "una manifestación de protesta por el alto costo de la vida, [...] que fue organizada por elementos de la Sección 2 del Sindicato de Trabajadores Ferrocarrileros”. Según la publicación, Luis Díaz, dirigente de la JUA expuso ampliamente las demandas de los vecinos, especialmente la clausura de los baños de Los Arquitos, "en vista del enorme volumen que se pierde ya que ni siquiera es utilizada por los propietarios de dichos baños, sino que limpia, sin usarse, es tirada a la acequia de Texas". De no ser posible lo anterior, continuaba Díaz, los baños deberían declararse de "utilidad pública", ya que con el agua que desperdiciaban podía abastecerse "una enorme cantidad de barrios de la ciudad". ${ }^{45}$

La movilización de los trabajadores fue fundamental para obligar a las autoridades locales a acelerar la búsqueda de una solución a la escasez de agua, que se agudizaba sobre todo en la parte oriente. Fue así como en septiembre de 1944, después de muchas dificultades y contratiempos, la colonia Gremial ya era abastecida con un pozo de 56 metros de profundidad, que rendía 35 litros de agua por segundo gracias a una bomba centrífuga acoplada a un motor de 100 caballos de fuerza. ${ }^{46}$

Las obras resultaban significativas porque por primera vez en la historia de la ciudad se utilizaba agua subterránea para abastecer una colonia. El hecho anunciaba lo que constituiría un cambio fundamental en el servicio de agua: el progresivo abandono del manantial del Ojocaliente como principal fuente de abasto y su sustitución por la explotación de mantos freáticos.

La puesta en marcha del pozo estuvo lejos de solucionar el problema de la escasez de agua, incluso para la colonia Gremial, cuyos habitantes quedaron sujetos a las continuas fallas del nuevo sistema. No resulta extraño en-

44 "Del presidente municipal Francisco Revilla al BNHOP", México, 1 de junio de 1943, AGMA, Fondo Histórico, caja 957, expediente 6, fs. 43f. El Banco Nacional Hipotecario se creó en 1933 a iniciativa del gobierno federal, con el objetivo de "contribuir a financiar las obras de infraestructura urbana [y] modernizar los servicios públicos". Con esta medida, se impulsó la intervención de las autoridades centrales en las finanzas y la política de los estados de la república. Véase Aboites y Loyo, "La construcción del nuevo Estado", p. 625.

45 Provincia, Aguascalientes, 12 de junio de 1943.

46 "Informe del ingeniero Guillermo Feuss, dirigido al gobernador Jesús María Rodríguez", México, 15 de septiembre de 1944, AHEA, Fondo Poder Ejecutivo, Secretaría General de Gobierno, sin clasificación. 
tonces, que en 1945 se presentara una nueva oleada de protestas, cuando las autoridades locales enfrentaron la oposición de los usuarios al tratar de elevar las cuotas de las mercedes de agua. Las negociaciones fueron más arduas y extensas, pues ayuntamiento y gobernador rechazaron las demandas y por primera vez enfrentaron manifestaciones de protesta organizadas en conjunto por la SUAF, los colonos de la Gremial y otras organizaciones de clase media y alta, como la Cámara de Propietarios de Fincas Urbanas o la Cámara de Comercio. ${ }^{47}$

Los argumentos, demandas y estrategias de los inconformes fueron similares a las desplegadas en la década de los treinta. Como en aquella ocasión, se denunció el abandono y deterioro del sistema de abasto, se solicitó al gobierno federal que el ayuntamiento de la capital cumpliera con la Ley de Aguas Federales, se exigió reducir las tarifas por mercedes de agua y legalizar el aprovechamiento del manantial del Ojocaliente. Las demandas fueron acompañadas de una huelga de pagos que inició en marzo de 1946 y se mantuvo por lo menos hasta junio de ese año.

Más allá del desenlace que tuvieron las protestas, interesa destacar que ya existía un repertorio compartido de peticiones, discursos y movilizaciones a través del cual los actores urbanos presentaban sus quejas y agravios a las autoridades locales. Este repertorio, que derivaba de la innovación tecnológica que hizo posible el abasto de agua a domicilio, fue pieza clave en la relación gobierno-sociedad e influyó en el abandono de la explotación de manantiales y el inicio de la utilización de agua subterránea, hecho que influyó decisivamente en la vida de la ciudad de Aguascalientes durante el resto del siglo XX.

\section{Palabras finales}

El surgimiento de sociedades de usuarios de agua y las protestas que protagonizaron adquieren un sentido histórico relevante si las ubicamos en el contexto del proceso de industrialización, crecimiento urbano y expansión del servicio de abasto domiciliario de agua ocurrido en la ciudad de Aguascalientes durante la primera mitad del siglo XX. Al alcanzar - de forma limitada y con muchas deficiencias - las nuevas colonias del norte y oriente de la capital, el servicio de agua entubada creó un tipo de demanda que fue adoptada tanto por las clases medias como por los grupos populares. Al hacerlo, los vecinos construyeron un discurso para relacionarse con las autoridades locales y reclamar su derecho a recibir de forma efectiva el nuevo servicio.

47 El Sol del Centro, Aguascalientes, 6 y 7 de julio de 1945. 
Este discurso remite a la existencia de hábitos, valores y costumbres que conformaron una cultura política caracterizada por tres rasgos fundamentales. Podemos señalar en primer lugar la presencia de un ideal urbano en donde la ciudad aparece como un espacio civilizado, higiénico y seguro, lo que se relacionaba, entre otras muchas cosas, con la supresión de huertas y baños públicos. Ambos lugares se convirtieron en blanco de la crítica de colonos y vecinos, que los señalaban por considerar que perjudicaban la salud pública y contribuían a la escasez de agua, necesaria para mejorar el funcionamiento del nuevo sistema de abasto a domicilio. El ideal urbano fue el motor fundamental que animó tanto la actuación de las autoridades locales como la intervención de los grupos urbanos, que aluden a ella para legitimar su derecho a recibir agua potable de manera eficaz y continua.

Lo anterior nos remite al segundo rasgo relevante de la cultura política urbana que aquí analizamos, pues la aspiración a vivir en un entorno higiénico era asumida como un derecho inherente a todos los habitantes de la ciudad. Bajo este supuesto, los usuarios de agua a domicilio exigían, a cambio de la tarifa que tenían que cubrir cada mes, que el gobierno cumpliera con su obligación de proporcionar servicios públicos eficientes y al alcance de los ciudadanos. Lo que en la actualidad puede parecer un reclamo normal, lógico o irrelevante, no lo era tanto durante la primera mitad del siglo XX, pues no debemos perder de vista que para esa época, el servicio de agua entubada era novedoso y las reglas que regían su funcionamiento estaban siendo construidas tanto por los usuarios como por las autoridades.

Finalmente hay que señalar las notorias deficiencias del sistema de abasto y sobre todo, la política tarifaria del ayuntamiento, que elevaba continuamente el costo de las mercedes de agua en busca de recursos extraordinarios para las agotadas arcas municipales. ${ }^{48} \mathrm{Al}$ hacerlo, el cabildo atentaba contra un tercer principio de la cultura política urbana que determinaba la relación entre autoridades y usuarios en torno al servicio del agua. Según dicho principio, el ayuntamiento debía garantizar un reparto justo del líquido y no estaba autorizado legítimamente a obtener ganancias de la administración del sistema de abasto.

Aunque sólo se cuenta con información fragmentaria sobre la política fiscal del ayuntamiento de la capital del estado durante las primeras décadas del siglo $\mathrm{XX}$, los datos disponibles apuntan a un constante incremento del costo de las mercedes de agua a domicilio. Se sabe, por ejemplo, que en 1906 una merced de primera clase costaba 3 pesos mensuales, mientras que para 1930 la misma merced costaba ya 5 pesos. Ver: Periódico Oficial del Estado, 24 de diciembre de 1916, 2 de diciembre de 1917, 8 de diciembre de 1918, 23 de noviembre de 1919, 9 de enero de 1921. AHA, AS, caja 4877, expediente 67890, fs. $127 \mathrm{v}$.; 17 de diciembre de 1931, "Tarifas que forman parte de los arbitrios del ayuntamiento de Aguascalientes para el año de 1932". 
$\mathrm{Al}$ gestionar el sistema de abasto como una fuente ingresos y no procurar la distribución justa del agua, el cabildo faltaba a sus obligaciones y violaba esta especie de "metacontrato" que regía sus relaciones con los vecinos. Esta política dio a los usuarios motivos suficientes para dejar de pagar las tarifas correspondientes y movilizarse para arrebatar al cabildo el control del servicio y obligarlo a buscar el apoyo de la federación para mejorar el servicio mediante la explotación de pozos.

También debe señalarse la influencia de las sociedades de usuarios y su cultura política en la evolución del sistema de abasto de agua. Como se analizó a lo largo del texto, los habitantes de la capital pugnaron no sólo para que el servicio de agua fuera eficiente y accesible, sino también para que el líquido se destinara sobre todo para usos domésticos. La exigencia implicaba disminuir el agua destinada a baños públicos y huertas, que comenzaron a ser vistas como espacios que amenazaban la higiene pública urbana. Para satisfacer estas demandas, autoridades locales y federales optaron por recurrir a la explotación de aguas subterráneas, que con el transcurso del siglo XX terminaron por desplazar a los manantiales del Ojocaliente.

La organización y movilización de sociedades de usuarios modificó el funcionamiento del sistema de abasto al impulsar dos transiciones fundamentales: una que implicó el desplazamiento de los usos agrícolas por los usos domésticos y otra que llevó a abandonar los manantiales y sus aguas superficiales y sustituirlos por la utilización de pozos y mantos freáticos.

Estamos aquí lejos de la imagen que hace aparecer a los grupos populares excluidos de los beneficios de la modernización urbana o en permanente actitud de resistencia ante los intentos de las autoridades por "reformar" o "higienizar" las ciudades. Lo que observamos, en el caso de Aguascalientes, es más bien lo contrario: los vecinos de la ciudad -incluso los de condición más humilde - exigían la presencia y actividad del gobierno, pues consideraban que era obligación de las autoridades locales proveer lo necesario para crear las condiciones que hicieran posible el advenimiento de la ciudad civilizada. Al hacerlo, influyeron en la orientación y funcionamiento del sistema de abasto de agua y por extensión, en la evolución de los espacios urbanos, la política y la vida cotidiana de la capital del estado de Aguascalientes.

\section{FUENTES}

\section{ARCHIVOS}

Archivo Histórico del Agua (AHA)

Fondo Aprovechamientos Superficiales (AS)

Archivo General Municipal de Aguascalientes (AGMA) 
Fondo Histórico (FH)

Archivo Histórico del Estado de Aguascalientes (AHEA)

Fondo Poder Ejecutivo (FPE)

Sección Secretaría General de Gobierno (SGG)

\section{HEMEROGRAFÍA}

Provincia, Aguascalientes, 1943.

El Sol del Centro, Aguascalientes, 1945-1946.

\section{BIBLIOGRAFÍA}

Aboites, Luis, El agua de la nación. Una historia política de México (1888-1946), México, CIESAS, 1998.

, "La ilusión del poder nacional. Provisión de agua y alcantarillado en México, 1930-1990", en Carlos Lira Vásquez y Ariel Rodríguez Kuri, Ciudades mexicanas del siglo XX. Siete estudios históricos, México, El Colegio de MéxicoUAM-Azcapotzalco/CONACyT, 2009, pp. 181-216.

, La decadencia del agua de la nación. Estudio sobre desigualdad social y cambio político en México. Segunda mitad del siglo XX, México, El Colegio de México, 2009.

Aboites, Luis y Engracia Loyo, "La construcción del nuevo Estado, 1920-1945”, en Erik Velásquez García, (et.al.), Nueva historia general de México, México, El Colegio de México, 2010, pp. 595-652.

Bernal Sánchez, Jesús, Apuntes históricos, geográficos y estadísticos del estado de Aguascalientes, Aguascalientes, Imprenta de Alberto E. Pedroza, 1928.

Broich, John, London. Water and the Making of the Modern City, University of Pittsburgh Press, 2013.

Camacho, Salvador, Controversia educativa entre la ideología y la fe. La educación socialista en la historia de Aguascalientes, 1876-1940, México, Consejo Nacional para la Cultura y las Artes, 1991.

Consejo Estatal de Población, 2002, el año del millón, Aguascalientes, COESPO, 2004.

Contreras-Utrera, Julio, Jesús R: Navarro y Sergio Rosas, (coords.), Agua, estado y Sociedad en América Latina y España, México, Escuela de Estudios Hispano-Americanos-Universidad Veracruzana, 2015.

Delgado, Francisco, "Policía urbana, usos del agua y cambio social. El proceso civilizatorio en la ciudad de Aguascalientes, 1880-1940”, Letras Históricas, núm. 19, otoño-invierno 2019, pp. 181-199.

Díaz de León, Jesús, “Apuntes para el estudio de la higiene de Aguascalientes por el Doctor Jesús Díaz de León, con la colaboración del Doctor Manuel Gómez 
Portugal", en Memoria que sobre los diversos ramos de la administración pública presenta a la honorable legislatura el C. Alejandro Vázquez del Mercado, gobernador constitucional del Estado de Aguascalientes por el período de $1^{\circ}$ de diciembre de 1887 a 30 de noviembre de 1891, Aguascalientes, Tipografía de Jesús Díaz de León, 1892.

Espinoza, Rodrigo, Ligeros apuntes para la geografía y estadística del estado de Aguascalientes, Aguascalientes, Edición de El Republicano, 1897.

Falcón, Romana, Revolución y caciquismo en San Luis Potosí. 1910-1938, México, El Colegio de México, 1984.

Gómez Serrano, Jesús, Remansos de ensueño. Las huertas y la gestión del agua en Aguascalientes, 1575-1960, México, Universidad Autónoma de Aguascalientes, 2018.

, Aguascalientes: imperio de los Guggenheim, México, SEP/80-Fondo de Cultura Económica, 1982.

, Aguascalientes en la historia 1786-1920, Sociedad y cultura, tomo III, volumen I, México, Instituto de Investigaciones José María Luis Mora, 1988.

Gómez Serrano, Jesús y Francisco Javier Delgado, Aguascalientes. Historia breve. México, El Colegio de México-Fondo de Cultura Económica, 2010.

Hobsbawm, Eric, Historia del siglo XX, Crítica, España, 1995.

Hornedo, Francisco G., Memoria que sobre los diversos ramos de la administración pública presenta a la Honorable Legislatura el C. Francisco G. Hornedo, gobernador constitucional del Estado de Aguascalientes, por el periodo de $1^{\circ}$ de diciembre de 1883 a 30 de noviembre de 1887, Aguascalientes, Imprenta de Trinidad Pedroza, 1887.

Lear, John, Workers, Neighbors, and Citizens. The Revolution in Mexico City, University of Nebraska Press, Lincoln and London, 2001.

Martínez Delgado, Gerardo, "Cambio y proyecto urbano. Aguascalientes, 18801914", tesis para optar al título de maestro en historia, Pontificia Universidad Javeriana, 2006.

Matés Barco, Juan Manuel, La conquista del agua. Historia económica del abastecimiento urbano, Jaén, Universidad de Jaén, 1999.

Melosi, Martín, The Sanitary City. Urban Infrastructure in America from Colonial Times to the Present, Baltimore \& London, The John Hopkins University Press, 2000.

, Precious Commmodity. Providing Water for America's Cities, University of Pittsburgh Press, 2011.

Newcomer, Daniel, Reconciling Modernity. Urban State Formation in 1940s León, Mexico, University of Nebraska Press, Lincoln and London, 2004.

Rodríguez Kuri, Ariel, Historia del desasosiego. La revolución en la ciudad de México, 1911-1922, México, El Colegio de México, 2010.

Salazar Sánchez, Antonio, El Aguascalientes de antaño (1920-1960), México, Instituto Cultural de Aguascalientes, 2003. 
Salmerón Castro, Fernando, Intermediario del progreso. Política y crecimiento urbano en Aguascalientes, México, ICA-CIESAS, 1998.

Sifuentes, Alejandro, "El período 1899-1950", en Elizabeth Buchanan y Jesús Gómez, (coordinadores), El desarrollo histórico de la vivienda en Aguascalientes, México, Gobierno del Estado de Aguascalientes, 1998, pp. 63-138.

Smith, Benjamin T., Pistoleros and Popular Movements. The Politics of State Formation in Postrevolutionary Oaxaca, University Of Nebraska Press, Lincoln and London, 2009.

Urbina Martínez, Gilberto, “Años veinte, organización vecinal y desarrollo urbano”, en Legajos. Boletín del Archivo General de la Nación, 7a época, núm. 1, julio-septiembre de 2009, pp. 27-43.

Velasco, Luis, Geografia y estadística de la República Mexicana, tomo XVII: Aguascalientes, México, Secretaría de Fomento, 1889.

Wood, Grant Andrew, Revolution in the Street. Women, Workers, and Urban Protest in Veracruz, 1870-1927, Scholarly Resources Inc., Wilmington, Delaware, 2002. 